\title{
Development of Novel Products from Agro-Wastes (Rice Husks) and Characterization in Kenya
}

\author{
Raphael Kungu ${ }^{1}$, Paul Njogu ${ }^{1}$ and Robert Kinyua ${ }^{2}$ \\ 1. Institute for Energy and Environmental Technology, Jomo Kenyatta University of Agriculture and Technology, Nairobi \\ 62000-00200, Kenya \\ 2. Academy Division, Jomo Kenyatta University of Agriculture and Technology, Nairobi 62000-00200, Kenya
}

\begin{abstract}
Rice growing is a popular agricultural activity in some areas in Kenya. The challenge is in the disposal of RH (Rice Husks). Rice production results in $20 \% \mathrm{RH}$ as byproduct. Simple incineration of RH results in RH ash which is a source of valuable chemical products. The ash is $87-97 \%$ silica, highly porous and light weight, with a very high external surface area. The end product of RHA (Rice Husk Ash) after chemical treatment, sodium silicate, is a precious commodity that has myriad applications especially in detergent manufacture and soap production. The objective was to determine the best conditions to synthesize silica from agro-wastes (RH) in Kenya. The yield $\left(\% \mathrm{SiO}_{2}\right)$ of the $\mathrm{HCl}$ (Hydrochloric Acid) leached $\mathrm{RH}$ at $500{ }^{\circ} \mathrm{C}$ was the highest at $99.2 \%$. Overall these conditions were the best in producing silicate. Percentage (\%) removal of each metal is different due to its chemical form in RH. The removal percentage of $\mathrm{K}$ is especially remarkable. And $0.5 \mathrm{M} \mathrm{HCl}$ leaching followed by thermal treatment of $600{ }^{\circ} \mathrm{C}$ gave the best increase in \% silica dioxide. The same process removed the most metallic impurities $\left(\mathrm{P}_{2} \mathrm{O}_{5}, \mathrm{~K}_{2} \mathrm{O}, \mathrm{CaO}, \mathrm{Mn}\right.$ and $\mathrm{Zn}$ ). Leaching with $0.5 \mathrm{M} \mathrm{HCl}$ followed with thermal treatment of $500{ }^{\circ} \mathrm{C}$ gave the best overall yield in $\%$ silica dioxide. An increase in temperature from $600{ }^{\circ} \mathrm{C}$ slightly reduced the \% silica dioxide content. The $0.5 \mathrm{M} \mathrm{HCl}$ used in these trials was able to produce 99.17\% silica content from the Mwea $\mathrm{RH}$. The $\mathrm{SiO}_{2}$ obtained with the water washed $\mathrm{RH}$ sample is $97.37 \%$ as compared $99.17 \%$ (HCl-washed) and 99.02\% ( $\mathrm{H}_{2} \mathrm{SO}_{4}$ (Sulphuric Acid)-leached). The FTIR (Fourier Transform Infrared Spectroscopy) spectra indicates $\mathrm{HCl}$ leaching avails more silica content than $\mathrm{H}_{2} \mathrm{SO}_{4}$ leaching.
\end{abstract}

Key words: RH conversion, acid leaching, silicate, sodium silicate, ideal conditions.

\section{Introduction}

Rice is a grass seed from Oryza sativa (Asian rice) species or Oryza glaberrima species also known as the African rice. Rice is grown widely across the globe and is usually a staple food for many people [1]. It is key to food security in many parts of the world mainly in Caribbean, Asia and Africa. According to Atera, et al. [2], the total annual world production of milled rice currently stands at 400 million metric tons which compares favorably well with maize and wheat. In addition, unlike maize and wheat that are consumed as human and livestock feed, rice remains the most favored grain globally for human consumption.

Consequently, in Kenya, rice is mostly grown by

Corresponding author: Raphael Kungu, Ph.D., research field: environmental technology. small-scale farmers in Coast (Tana delta, Msambweni), Nyanza provinces (Ahero, West Kano, Migori and Kuria), Central (Mwea) and in Western (Bunyala). As indicated by Atera, et al. [2] and Majiwa, et al. [3] there are four main rice mills across Kenya and their capacities varies. For example, Western Kenya rice mills have a milling capacity of up to 3 metric tons, LBDA (Lake Basin Development Authority) has a milling capacity of 3.5 metric tons, Tana Delta with 3 metric tons and Mwea NIB (National Irrigation Board) mills up to 24 metric tons. Moreover, there are quite a number of rice traders across the country. The major traders consist of government owned NCPB (National Cereals and Produce Board), LBDA through their rice mills in Ahero, Mwea and Kibos processes and supplies milled rice to local supermarkets and retailers, NIB, Dominion Farms and Capwell Industries, Mwea 
Farmers' Multipurpose Cooperative Society, Supermarkets in major urban centers among others.

According to Gewona [4], about $95 \%$ of rice grown in Kenya is irrigated. Private irrigated farms exist like Dominion Farms, Yala swamp region near Lake Victoria, LBDA as well as Mwea in central Kenya that has $78 \%$ of all irrigated farms. As a matter of fact, rice farming plays a vital role in poverty alleviation. Therefore, there is increased acceptance that rice and its products are a strategic commodity to fuel economic growth and contribute towards hunger and poverty reduction in Kenya. As a result, Kenya has embarked on an ambitious program to boost rice production capacity.

Rice has an outer layer known as the RH (Rice Husk) (or Hull). The RH is normally separated from the rice grains during the process of milling. About $20 \%$ of paddy weight is husk. Previously, Gummert and Rickman [5] indicated how RH has been largely considered as a waste product that has been often dumped or burned on landfills. However, $\mathrm{RH}$ is nowadays considered as an economic viability product and also as a product that helps in controlling environmental pollution in many countries. Therefore, some enterprising companies are turning it into various products not only for the eco-conscious market place but also for the industrial sector [6].

In Kenya, the production of rice has resulted in an increased production of RHs which have been in many cases with wastes considered $[1,7]$. Additionally, RH management in the country has not been viable and sustainable and has majorly been via open incineration which has led to environmental pollution as well as release of greenhouse gases. Further, there is a proposition by UNEP (United Nations Environmental Program) for countries to recover valuable materials from the waste stream so as to enhance waste to wealth conversion. The UNEP suggestion is in tandem with the Vision 2030 that also aspires Kenya to move into an industrialized nation which can solely be supported through small and micro enterprises [2, 7].
Njogu, et al. [8] state that RH ones incinerated produce RHA (Rice Husk Ash) that contains high heat content that can be processed and utilized for industrial purposes. Literature has also pointed out that RHA has $80 \%$ silica content that can be converted to sodium silicate and other silica related products [9]. The end product of RHA, sodium silicate, is a precious commodity that has myriad applications especially in detergent manufacture and soap production. In addition, $\mathrm{RH}$ also helps in the production of activated carbon. There is a big market for the products of this study. It is hoped that the excess heat and chemical products generated in the project will be used for electricity generation, treatment of environment and in the production of detergents among other economic products.

\subsection{Study Area and Population}

The target population was all the rice growers in Mwea in Kenya. These included the rice milling areas in Mwea NIB which has 24 metric tons of rice production. The target population is concentrated in the two main towns of Wanguru and Ngurubani. The population is estimated to be over 200,000 . There has been an influx of people to the towns. There has been growth in various agro-industries in the towns especially rice milling. Agriculture has developed rapidly and among other crops grown are tomatoes, onions, French beans and other horticultural crops.

Rice milling leads to the production of RHs which are unwanted by-product that can create environmental pollution problems. So as to help in curtailing the danger that RH may subject humans to and control environmental pollution, it is important to explore ways of generating chemical materials from RHs.

\section{Methods}

\subsection{Sample Collection}

About $20 \mathrm{~kg}$ of RHs were collected from (1) Mwea rice millers (Kirinyaga County), (2) Euro rice Millers (Kirinyaga County), (3) Jkuat bright project (Kiambu 
County), (4) Nice rice millers (Kirinyaga County) in Kenya.

Sample collected were divided into two portions and under-went different thermal treatments after being acid leached.

\subsubsection{Un-leached Samples Preparation}

The samples were washed for 10 min with tap water to remove soils adhering to the husks and rinsed with distilled water. Drying of the samples was done initially at room temperature and subsequently at an air oven (Memmert UF110) at $110^{\circ} \mathrm{C}$ for $24 \mathrm{~h}$.

\subsubsection{Leached Samples Preparation}

The samples were further divided in two portions and separately leached with general purpose acid reagents (GPR) namely $(0.5 \mathrm{M} \mathrm{HCl})$ Hydrochloric Acid and $\left(0.5 \mathrm{M} \mathrm{H}_{2} \mathrm{SO}_{4}\right)$ Sulphuric Acid. This was done by mixing the sample and acid at $60{ }^{\circ} \mathrm{C}$ for 30 min with constant stirring. The acid solution was removed by washing with water, rinsing with distilled water until free from acids. Litmus paper was used to ensure the acidity was removed. The leached samples were then filtered and then air-dried for $24 \mathrm{~h}$ at room temperature. Final drying was then done for $2 \mathrm{~h}$ at $110^{\circ} \mathrm{C}$ in an oven (Memmert UF110).

The acid leached and unleached samples were then charred in a combustion chamber for $30 \mathrm{~min}$ to remove carbonaceous matter and subsequently thermally treated at an electronic muffle furnace (Advantec KL-420) at $500{ }^{\circ} \mathrm{C}, 600{ }^{\circ} \mathrm{C}$ and $700{ }^{\circ} \mathrm{C}$ for 30 min.

Fernandes, et al. [10] have determined that a pretreatment like acid or alkaline leaching followed by thermal treatment increases the amount of silica produced by reduction of carbonaceous materials. Their results also showed that it is possible to produce silica from RHA using simple methods, and that the produced silica has purity above $98 \%$.

The samples were analyzed for silica content using an Brukers X-ray Fluorescence S1 Titan instrument. Since XRF is a non-destructive technique, it is ideal for analyzing and sorting incoming material, finished goods and in-process production parts.

\subsection{Sample Treatment and TXRF (Total X-Ray Fluorescence) Analysis}

\subsubsection{Rice Ash Prepared from RH}

Acid leaching was done by treating the RRH (Raw $\mathrm{RH})$ with dilute $\mathrm{HCl}$ (1:1) in distilled water for $1 \mathrm{~h}$. It was then washed thoroughly with distilled water. The process was repeated with dilute $\mathrm{H}_{2} \mathrm{SO}_{4}$. The treated husk was then taken out and washed thoroughly in distilled water followed by drying in air for $24 \mathrm{~h}$. About $5 \mathrm{~g}$ samples of RRH and ARH (Acid-Treated Rice Husk) were then taken in separate cylindrical alumina crucibles and introduced into a muffle furnace for pyrolysis at different temperatures varying from 400,500 to $700{ }^{\circ} \mathrm{C}$ at an interval of $100{ }^{\circ} \mathrm{C}$ for 2 $\mathrm{h}$ soaking time in static air.

\subsubsection{Sodium Silicate Solution from Rice Ash}

RH was burnt openly and the ash leached with water. The leached samples were treated with different concentrations of $\mathrm{NaOH}$ to find the optimum amount needed to produce the best quality sodium silicate solution.

RH was also thermally treated, charred in a combustion chamber for $30 \mathrm{~min}$ to remove carbonaceous matter and subsequently ashed at an electronic muffle furnace (Advantec KL-420) at $400{ }^{\circ} \mathrm{C}, 500{ }^{\circ} \mathrm{C}$ and $600{ }^{\circ} \mathrm{C}$ for $30 \mathrm{~min}$.

The samples were then leached with distilled water. Sixty (60) g of leached RHA was mixed with $300 \mathrm{~mL}$ of $1 \mathrm{M}, 2 \mathrm{M}, 3 \mathrm{M} \mathrm{NaOH}$ solution in a pyrex $500 \mathrm{~mL}$ beaker. The solution was boiled at $100{ }^{\circ} \mathrm{C}$ for $1 \mathrm{~h}$ with constant mixing. The solutions were then decanted into sample bottles and analyzed by using an XRF S1 TITAN.

\section{Results and Discussion}

\section{$3.1 \% \mathrm{SiO}_{2}$ Yields with Three Treatments}

The $\mathrm{HCl}$ leached sample produced more $\% \mathrm{SiO}_{2}$ as shown in Fig.1. Acid leaching is an efficient method of removing metallic impurities before combustion 


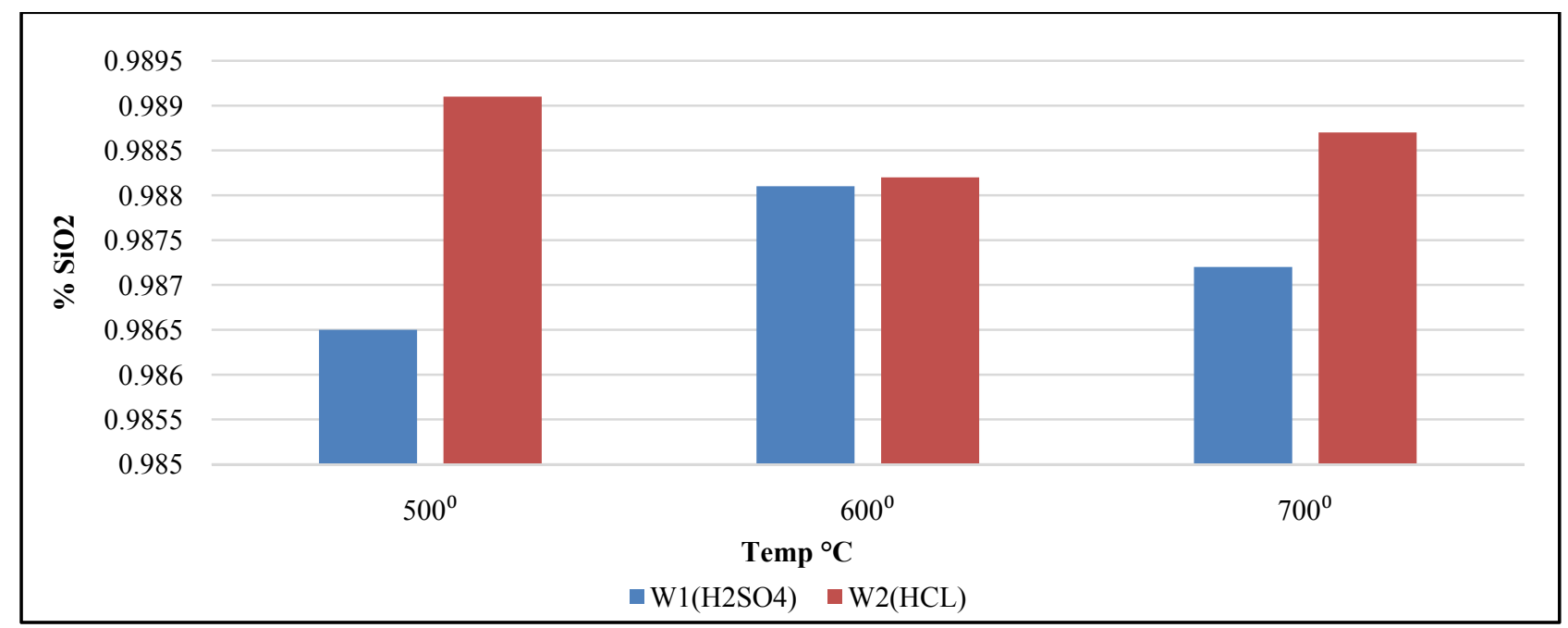

Fig. $1 \mathrm{SiO}_{2}(\mathrm{~g} / \mathrm{g})$ content after leaching $\left(0.5 \mathrm{M} \mathrm{HCl,} 0.5 \mathrm{M} \mathrm{H}_{2} \mathrm{SO}_{4}\right)$, after thermal treatment.

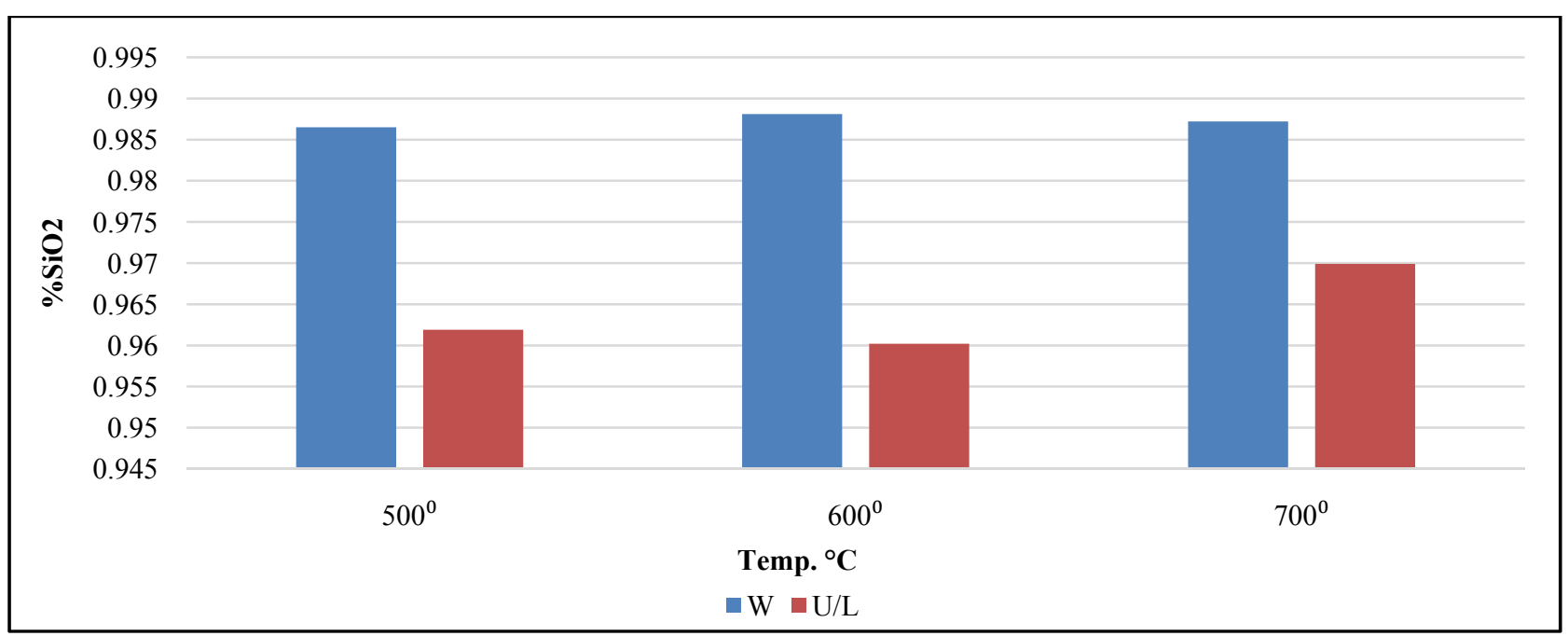

Fig. $2 \mathrm{SiO}_{2}(\mathrm{~g} / \mathrm{g})$ content of the $\mathrm{H}_{2} \mathrm{SO}_{4}$ treated samples at three temperatures.

and incinerating the RH. Results have showed that, the percentage yield of silica is high when acid washed RHA is used as compared with un-leached RHA [10].

Fig. 2 shows significant $\%$ content differences between the un-leached (W) and acid leached samples (U/L).

Statistical analysis of the two data sets from Fig. 2 at the three different temperatures produced the above results. $F=0.023978$ less $F$ critical one implies there is significant difference between the values at 95\% confidence level. This implies acid leaching causes a significant difference to the $\mathrm{SiO}_{2}$ content at the three temperatures. Yalçin and Sevinc [11] demonstrated that incineration of $\mathrm{RH}$ at between $600{ }^{\circ} \mathrm{C}$ and $800{ }^{\circ} \mathrm{C}$ preceded by chemical and thermal pretreatment produces high purity silica. The authors used different chemical and thermal treatment approaches, but reported that acid leaching pretreatment followed by oxygen-rich incineration and combustion of RH produced the highest silica content. One of the reasons why it is more difficult to obtain silica with purity above $97 \%$ from $\mathrm{RH}$ by direct incineration is the presence of metallic contaminants, especially potassium and sodium oxides [12]. These compounds affect the surface of silica particles, 
increasing their surface area and reactivity, and thereby increase silica crystallization rate. Acid leaching followed by thermal treatment induced the production of silica with the lowest carbon level [1, 13]. The fact is that acid leaching prevents the formation of black particles, since it removes potassium, the main agent responsible for the presence of unburnt carbon in ash.

Fernandes, et al. [14] found that a pretreatment strategy to remove metallic contaminants using acid leaching results in high purity silica with particles of larger specific surface area. A study done by the authors shows that it is possible to produce silica from RHA using simple processes. The various production methods tested resulted in silica with purity above $98 \%$, especially acid leaching followed by thermal treatment. Using $0.5 \mathrm{M} \mathrm{HCl}$ as a leaching agent gave the best result.

Acid leaching followed by thermal treatment induced the production of silica with the lowest carbon level (0.09\%). Atera, et al. [2] and Krishnarao, et al. [13] explained that acid leaching prevents the formation of black particles, since it removes potassium, the main agent responsible for the presence of unburnt carbon in ash. The authors showed that potassium works as catalyst in the crystallization of silica and, when temperature rises above the dissociation temperature of $\mathrm{K}_{2} \mathrm{O}$ (approximately $347{ }^{\circ} \mathrm{C}$ ), the surface of ash particles begins to melt, blocking the transportation of oxygen and $\mathrm{CO}_{2}$ and increasing the amount of unburnt carbon.

\section{$3.2 \%$ Elemental Content Resulting from the Treatments}

At $500{ }^{\circ} \mathrm{C}$ F crit (3.5545) is slightly greater than $\mathrm{F}$ (2.12) this implies the treatments do not differ significantly in their effect. The yield $\left(\% \mathrm{SiO}_{2}\right)$ of the $\mathrm{HCl}$ leached $\mathrm{RH}$ at this temperature was the highest at $99.2 \%$. Overall these conditions were the best in producing silicate.

The results suggest that the removal degree of each metal is different due to each of its chemical form in RH. The removal percentage of $\mathrm{K}$ is especially remarkable.

Muhammad [16] has described how thermal decomposition of raw $\mathrm{RH}$ starts at about $230{ }^{\circ} \mathrm{C}$ which is quite late compared to $\mathrm{ARH}\left(200{ }^{\circ} \mathrm{C}\right)$. Moreover, the ARH undergoes greater mass loss. In case of ARH, commencement of thermal decomposition at lower temperature can be ascribed to two factors: (i) acid leaching of partially oxidized carbohydrates and (ii) activated amide groups in $\mathrm{RH}$ such as $-\mathrm{NH}_{2}$ and $-\mathrm{CN}$. Authors like Riveros and Garza [17], Chakraverty, et al. [18] and Krishnaroa, et al. [19] have concluded that preliminary simple acid leaching of $\mathrm{RH}$ before thermal treatment is highly effective in substantially removing most of the metallic impurities and producing silica ash with a high specific surface area $\left(<250 \mathrm{~m}^{2} / \mathrm{g}\right)$ and small particle sizes $(<5 \mathrm{~nm})$. There are several leaching agents that can be used in the extraction of inorganic impurities from $\mathrm{RH}$ such as $\mathrm{HCl}, \mathrm{H}_{2} \mathrm{SO}_{4}$ and $\mathrm{HNO}_{3}$. Using $\mathrm{H}_{2} \mathrm{SO}_{4}$ leads to formation of metallic sulphates $\left(\mathrm{CaSO}_{4}\right)$, some of which are not easily soluble in water. $\mathrm{HCl}$ is cheaper and more effective [15]. The authors also found that:

The silica content of husk ash can be increased from $88.03 \%$ to $99.70 \%$ by $\mathrm{HCl}$ treatment before calcination process.

The amount of element removed after both acid treatments at different thermal temperatures is calculated from the previous Tables 1-3 and tabulated below.

From the results it is apparent that $0.5 \mathrm{M} \mathrm{HCl}$ leaching followed by thermal treatment of $600{ }^{\circ} \mathrm{C}$ (Table 5) gave the best increase in \% silica dioxide. The same process removed the most metallic impurities $\left(\mathrm{P}_{2} \mathrm{O}_{5}, \mathrm{~K}_{2} \mathrm{O}, \mathrm{CaO}, \mathrm{Mn}\right.$ and $\left.\mathrm{Zn}\right)$. Leaching with $0.5 \mathrm{M} \mathrm{HCl}$ followed with thermal treatment of $500{ }^{\circ} \mathrm{C}$ (Table 4) gave the best overall yield in \% silica dioxide. An increase in temperature from $600{ }^{\circ} \mathrm{C}$ (Table 6) slightly reduced the \% silica dioxide content. 
Table $1 \%$ Elemental content of un-leached and acid leached RHA at $500{ }^{\circ} \mathrm{C}$.

\begin{tabular}{llll}
\hline \% Element & Un-leached & HCl-leached & H $_{\mathbf{2}} \mathbf{S O}_{4}$-leached \\
\hline $\mathbf{S i O}_{2}$ & $97.372 \pm 1.489$ & $99.173 \pm 1.325$ & $99.020 \pm 1.348$ \\
$\mathbf{M g O}$ & $*$ & $*$ & $*$ \\
$\mathbf{A l}_{2} \mathbf{O}_{3}$ & $0.172 \pm 0.431$ & $0.117 \pm 0.382$ & $0.247 \pm 0.052$ \\
$\mathbf{P}_{\mathbf{2}} \mathbf{O}_{\mathbf{5}}$ & $0.430 \pm 0.070$ & $0.204 \pm 0.049$ & $0.161 \pm 0.015$ \\
$\mathbf{K}_{\mathbf{2}} \mathbf{O}$ & $1.177 \pm 0.034$ & $0.141 \pm 0.015$ & $0.290 \pm 0.017$ \\
$\mathbf{C a O}$ & $0.582 \pm 0.025$ & $0.235 \pm 0.016$ & $0.037 \pm 0.008$ \\
$\mathbf{M n}$ & $0.088 \pm 0.013$ & $0.030 \pm 0.007$ & $0.095 \pm 0.009$ \\
$\mathbf{F e}$ & $0.125 \pm 0.011$ & $0.082 \pm 0.008$ & $0.006 \pm 0.002$ \\
$\mathbf{Z n}$ & $0.011 \pm 0.003$ & $0.004 \pm 0.002$ & $*$ \\
$\mathbf{C l}$ & $0.027 \pm 0.027$ & $*$ & $*$ \\
$\mathbf{N a}$ & $*$ & $*$ & $0.113 \pm 0.025$ \\
$\mathbf{S}$ & $*$ & $0.027 \pm 0.020$ & \\
\hline
\end{tabular}

* Not detectable;

$\%$ Elemental Content of 0.5 M HCl-Leached, 0.5 $\mathrm{M} \mathrm{H}_{2} \mathrm{SO}_{4}$-Leached and Un-leached RH Samples at $500{ }^{\circ} \mathrm{C}$.

Table $2 \%$ Elemental content of un-leached and acid (0.5 M HCl \& $\left.0.5 \mathrm{M} \mathrm{H}_{2} \mathrm{SO}_{4}\right)$ leached $\mathrm{RHA}$ at $600{ }^{\circ} \mathrm{C}$.

\begin{tabular}{llll}
\hline \% Element & Un-leached & HCl-leached & H $_{\mathbf{2}} \mathbf{S O}_{4}$-leached \\
\hline $\mathbf{S i O}_{\mathbf{2}}$ & $95.933 \pm 1.464$ & $98.899 \pm 1.330$ & $98.237 \pm 1.332$ \\
$\mathbf{M g O}$ & $*$ & $*$ & $*$ \\
$\mathbf{A l}_{\mathbf{2}} \mathbf{O}_{\mathbf{3}}$ & $*$ & $0.402 \pm 0.390$ & $0.506 \pm 0.388$ \\
$\mathbf{P}_{\mathbf{2}} \mathbf{O}_{\mathbf{5}}$ & $0.622 \pm 0.085$ & $0.252 \pm 0.052$ & $0.256 \pm 0.054$ \\
$\mathbf{K}_{\mathbf{2}} \mathbf{O}$ & $2.172 \pm 0.052$ & $0.107 \pm 0.015$ & $0.185 \pm 0.015$ \\
$\mathbf{C a O}$ & $0.817 \pm 0.029$ & $0.245 \pm 0.016$ & $0.418 \pm 0.019$ \\
$\mathbf{M n}$ & $0.138 \pm 0.016$ & $0.027 \pm 0.007$ & $0.059 \pm 0.008$ \\
$\mathbf{F e}$ & $0.093 \pm 0.010$ & $0.133 \pm 0.012$ & $0.127 \pm 0.009$ \\
$\mathbf{Z n}$ & $0.016 \pm 0.004$ & $0.005 \pm 0.002$ & $0.006 \pm 0.002$ \\
$\mathbf{C l}$ & $0.048 \pm 0.039$ & $*$ & $*$ \\
$\mathbf{N a} \mathbf{a}_{\mathbf{O}} \mathbf{O}$ & $*$ & $*$ & $*$ \\
$\mathbf{S}$ & $95.933 \pm 1.464$ & $98.899 \pm 1.330$ & $98.237 \pm 1.332$ \\
\hline
\end{tabular}

* Not detectable;

$\%$ Elemental Content of 0.5 M HCl-Leached, 0.5 $\mathrm{M} \mathrm{H}_{2} \mathrm{SO}_{4}$-Leached and Un-leached RH Samples at $600{ }^{\circ} \mathrm{C}$.

Table $3 \%$ Elemental content of un-leached and acid leached RHA at $700{ }^{\circ} \mathrm{C}$.

\begin{tabular}{llll}
\hline \% Element & Un-leached & HCl-leached & $\mathbf{H}_{\mathbf{2}} \mathbf{S O}_{4}$-leached \\
\hline $\mathbf{S i O}_{\mathbf{2}}$ & $96.266 \pm 1.40$ & $98.999 \pm 1.358$ & $98.647 \pm 1.332$ \\
$\mathbf{M g O}$ & $*$ & $*$ & $*$ \\
$\mathbf{A l}_{\mathbf{2}} \mathbf{O}_{\mathbf{3}}$ & $*$ & $0.243 \pm 0.387$ & $0.073 \pm 0.389$ \\
$\mathbf{P}_{\mathbf{2}} \mathbf{O}_{\mathbf{5}}$ & $0.563 \pm 0.075$ & $0.242 \pm 0.051$ & $0.295 \pm 0.056$ \\
$\mathbf{K}_{\mathbf{2}} \mathbf{O}$ & $1.936 \pm 0.042$ & $0.142 \pm 0.015$ & $0.227 \pm 0.017$ \\
$\mathbf{C a O}$ & $0.773 \pm 0.027$ & $0.251 \pm 0.017$ & $0.477 \pm 0.020$ \\
$\mathbf{M n}$ & $0.130 \pm 0.015$ & $0.086 \pm 0.008$ & $0.058 \pm 0.010$ \\
$\mathbf{F e}$ & $0.119 \pm 0.012$ & $0.120 \pm 0.009$ & $0.108 \pm 0.009$ \\
$\mathbf{Z n}$ & $0.014 \pm 0.003$ & $0.005 \pm 0.002$ & $0.008 \pm 0.002$ \\
$\mathbf{C l}$ & $0.024 \pm 0.033$ & $*$ & $0.002 \pm 0.032$ \\
$\mathbf{N a} \mathbf{O}$ & $*$ & $*$ \\
$\mathbf{S}$ & $*$ & $*$ & $*$ \\
$*$ Not detectable; & $*$ &
\end{tabular}


Table $4 \%$ Elemental content change after the $0.5 \mathrm{M} \mathrm{HCl}$ and $0.5 \mathrm{M} \mathrm{H}_{2} \mathrm{SO}_{4}$ leaching followed by $500{ }^{\circ} \mathrm{C}$ thermal treatment.

\begin{tabular}{lll}
\hline$\%$ Element & $500{ }^{\circ} \mathrm{C}$ & \\
\cline { 2 - 3 } & $\mathrm{HCl}$ & $\mathrm{H}_{2} \mathrm{SO}_{4}$ \\
\hline $\mathrm{SiO}_{2}$ & $1.801(1.85 \%)$ & $1.648(1.69 \%)$ \\
$\mathrm{MgO}$ & $\mathrm{ND}$ & $\mathrm{ND}$ \\
$\mathrm{Al}_{2} \mathrm{O}_{3}$ & $-0.055(-32 \%)$ & $\mathrm{ND}$ \\
$\mathrm{P}_{2} \mathrm{O}_{5}$ & $-0.226(-52 \%)$ & $-0.183(-42 \%)$ \\
$\mathrm{K}_{2} \mathrm{O}$ & $-1.036(-88 \%)$ & $-1.016(-86 \%)$ \\
$\mathrm{CaO}$ & $-0.347(-60 \%)$ & $-0.292(-50 \%)$ \\
$\mathrm{Mn}$ & $-0.058(-66 \%)$ & $-0.051(-58 \%)$ \\
$\mathrm{Fe}$ & $-0.043(-34 \%)$ & $-0.030(-24 \%)$ \\
$\mathrm{Zn}$ & $-0.007(-63 \%)$ & $-0.005(-45 \%)$ \\
\hline
\end{tabular}

ND- Not detected.

Table $5 \%$ Elemental content change after the $0.5 \mathrm{M} \mathrm{HCl}$ and $0.5 \mathrm{M} \mathrm{H}_{2} \mathrm{SO}_{4}$ leaching followed by $600{ }^{\circ} \mathrm{C}$ thermal treatment.

\begin{tabular}{lll}
\hline \multirow{2}{*}{$\%$ Element } & $600{ }^{\circ} \mathrm{C}$ & \\
\cline { 2 - 3 } & $\mathrm{HCl}$ & $\mathrm{H}_{2} \mathrm{SO}_{4}$ \\
\hline $\mathrm{SiO}_{2}$ & $2.966(3.09 \%)$ & $2.304(2.40 \%)$ \\
$\mathrm{MgO}$ & $\mathrm{ND}$ & $\mathrm{ND}$ \\
$\mathrm{Al}_{2} \mathrm{O}_{3}$ & $\mathrm{ND}$ & $\mathrm{ND}$ \\
$\mathrm{P}_{2} \mathrm{O}_{5}$ & $-0.370(-59 \%)$ & $-0.366(-59 \%)$ \\
$\mathrm{K}_{2} \mathrm{O}$ & $-2.065(-95 \%)$ & $-1.987(-91 \%)$ \\
$\mathrm{CaO}$ & $-0.572(-70 \%)$ & $-0.399(-49 \%)$ \\
$\mathrm{Mn}$ & $-0.111(80 \%)$ & $-0.079(-57 \%)$ \\
$\mathrm{Fe}$ & $-0.04(-43 \%)$ & $0.034(36 \%)$ \\
$\mathrm{Zn}$ & $-0.011(-68 \%)$ & $-0.01(-62 \%)$ \\
\hline
\end{tabular}

ND- Not detected.

Table $6 \%$ Elemental content change after the $0.5 \mathrm{M} \mathrm{HCl}$ and $0.5 \mathrm{M} \mathrm{H}_{2} \mathrm{SO}_{4}$ leaching followed by $700{ }^{\circ} \mathrm{C}$ thermal treatment.

\begin{tabular}{lll}
\hline$\%$ Element & $700{ }^{\circ} \mathrm{C}$ & \\
\cline { 2 - 3 } & $\mathrm{HCl}$ & $\mathrm{H}_{2} \mathrm{SO}_{4}$ \\
\hline $\mathrm{SiO}_{2}$ & $2.733(2.84 \%)$ & $2.381(2.47 \%)$ \\
$\mathrm{MgO}$ & $\mathrm{ND}$ & $\mathrm{ND}$ \\
$\mathrm{Al}_{2} \mathrm{O}_{3}$ & $\mathrm{ND}$ & $\mathrm{ND}$ \\
$\mathrm{P}_{2} \mathrm{O}_{5}$ & $-0.321(-57 \%)$ & $-0.268(-47 \%)$ \\
$\mathrm{K}_{2} \mathrm{O}$ & $-1.794(-92 \%)$ & $-1.709(-88 \%)$ \\
$\mathrm{CaO}$ & $-0.522(-67 \%)$ & $-0.296(-38 \%)$ \\
$\mathrm{Mn}$ & $-0.044(-34 \%)$ & $-0.072(-55 \%)$ \\
$\mathrm{Fe}$ & $0.001(0.8 \%)$ & $-0.011(-9 \%)$ \\
$\mathrm{Zn}$ & $-0.009(-64 \%)$ & $-0.006(-42 \%)$ \\
\hline
\end{tabular}

ND- Not detected.

Kurama, H., and Kurama, S. K. [15] found that the silica percent of RH does not show any linear relationship with molarities of acid used during the treatment. However, the silica content of ash is increased from $88.02 \%$ to $99.50 \%$ for $2 \mathrm{M} \mathrm{HCl}$ concentration.
The $0.5 \mathrm{M} \mathrm{HCl}$ used in these trials was able to produce $99.17 \%$ silica content from the Mwea RHs.

The $\mathrm{SiO}_{2}$ obtained with the water washed $\mathrm{RH}$ sample is $97.37 \%$ as compared with $99.17 \%$ (HCl-washed) and $99.02 \%\left(\mathrm{H}_{2} \mathrm{SO}_{4}\right.$-leached). 


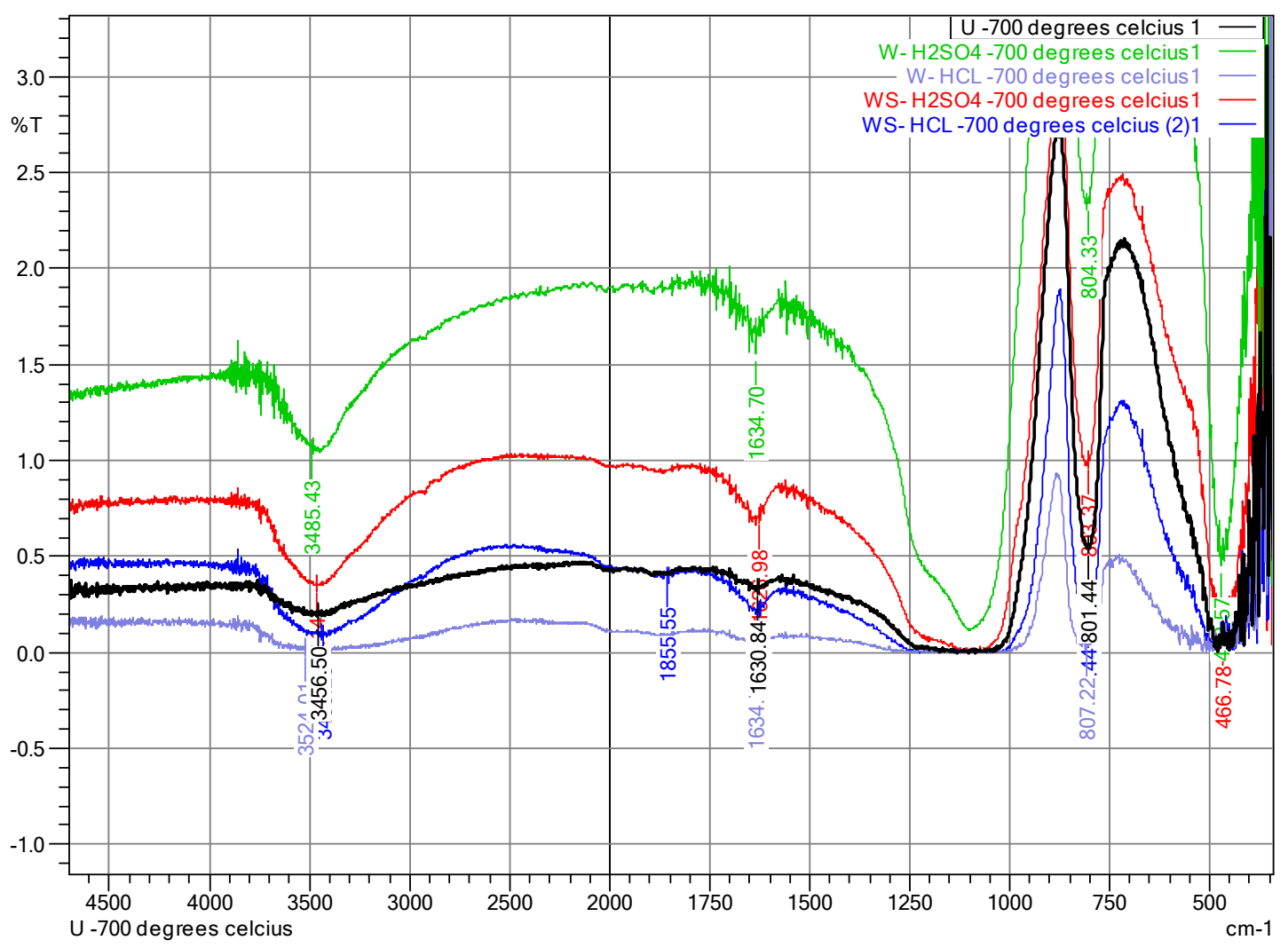

Fig. 3 FTIR spectra of the different treatments.

\subsection{Characterization of the Samples (Silica) Using FTIR (Fourier Transform Infrared Spectroscopy)}

The acid leached/un-leached samples were pressed in a hydraulic press between smooth stainless steel dies (at 10 tons pressure for $2 \mathrm{~min}$ ) to give a clear $\mathrm{KBr}$ disk. The samples were then read using the FTIR spectrophotometer IRTracer-100. The results are as displayed below.

The four main characteristic absorption bands indicate presence of an inorganic compound. Broad absorption bands at above $3,000 \mathrm{~cm}^{-1}$ imply an unsaturated $\mathrm{C}-\mathrm{H}$ possibly from the hydrocarbons of the soap used. The moderate to intense bands at 1,600-1,300, 1,200-1,000 and $800-600 \mathrm{~cm}^{-1}$ also indicate presence of a hydroxyl compound. The relatively narrow absorption at 1,626 $\mathrm{cm}^{-1}$ indicates olefin unsaturation and aromatic compound possibly of the detergent used. The multiple bands between $1,000-880 \mathrm{~cm}^{-1}$ indicate $\mathrm{C}-\mathrm{H}$ out-of-plane bending. The absorption at 1,100-900 $\mathrm{cm}^{-1}$ is a marker for the presence of silicate ion. An e-FTIR (Fourier Transform Infra-Red) software scan gave the following report.

FTIR spectra of pure silica typically exhibit peaks in two distinct regions (Fidalgo and Ilharco, [20]; Swan and Patwardhan: [21] peaks at $>2,500 \mathrm{~cm}^{-1}$ and $\left.<1,300 \mathrm{~cm}^{-1}\right)$. The first region corresponds to $-\mathrm{OH}$ (Hydroxyl) stretching from absorbed or molecular water, while the second region occurs due to several silica modes. While containing a number of peaks, the silica region can be primarily separated into three peaks at: a broad peak at $\sim 1,100 \mathrm{~cm}^{-1}$ and $\sim 450 \mathrm{~cm}^{-1}$, $\sim 800 \mathrm{~cm}^{-1}$. The absorption at $\sim 450 \mathrm{~cm}^{-1}$ has been assigned to rocking motion of oxygen atoms. The symmetric vibrations of silicon atoms in a silixane bond occur at $\sim 800 \mathrm{~cm}^{-1}$. The largest peak observed in a silica spectrum is present at $\sim 1,100 \mathrm{~cm}^{-1}$.

The average FTIR instrument records spectra from an upper limit of around $4,000 \mathrm{~cm}^{-1}$ down to $400 \mathrm{~cm}^{-1}$ 
as defined by the optics of the instrument (commonly based on potassium bromide, $\mathrm{KBr}$ ).

\section{Conclusions}

The FTIR spectra also indicate $\mathrm{HCl}$ leaching avails more silica content than $\mathrm{H}_{2} \mathrm{SO}_{4}$ leaching. Washing with soap and leaching with $\mathrm{HCl}$ seems to decrease silica content. There is less transmittance when $\mathrm{RH}$ is initially leached with $\mathrm{HCl}$. The results suggest that the removal degree of each metal is different due to each of its chemical form in RH. The removal percentage of $\mathrm{K}$ is especially remarkable.

From the results, it is apparent that $0.5 \mathrm{M} \mathrm{HCl}$ leaching followed by thermal treatment of $600{ }^{\circ} \mathrm{C}$ gave the best increase in \% silica dioxide. The same process removed the most metallic impurities $\left(\mathrm{P}_{2} \mathrm{O}_{5}\right.$, $\mathrm{K}_{2} \mathrm{O}, \mathrm{CaO}, \mathrm{Mn}$ and $\mathrm{Zn}$ ). Leaching with $0.5 \mathrm{M} \mathrm{HCl}$ followed with thermal treatment of $500{ }^{\circ} \mathrm{C}$ gave the best overall yield in \% silica dioxide. An increase in temperature from $600{ }^{\circ} \mathrm{C}$ slightly reduced the $\%$ silica dioxide content.

The $0.5 \mathrm{M} \mathrm{HCl}$ used in these trials was able to produce $99.17 \%$ silica content from the Mwea $\mathrm{RH}$.

The $\mathrm{SiO}_{2}$ obtained with the water washed $\mathrm{RH}$ sample is $97.37 \%$ as compared with $99.17 \%$ ( $\mathrm{HCl}$-washed) and $99.02 \%\left(\mathrm{H}_{2} \mathrm{SO}_{4}\right.$-leached).

\section{References}

[1] Kamath, S. R., and Proctor, A. 1998. "Silica Gel from Rice Hull Ash: Preparation and Characterization." Cereal Chemistry 75 (4): 484-7.

[2] Atera, E. A., Onyancha, F. N., and Majiwa, E. B. 2018. "Production and Marketing of Rice in Kenya: Challenges and Opportunities." Journal of Development and Agricultural Economics 10 (3): 64-70.

[3] Majiwa, E., Lee, B. L., Wilson, C., Fujii, H., and Managi, S. 2018. "A Network Data Envelopment Analysis (NDEA) Model of Post-Harvest Handling: The Case of Kenya's Rice Processing Industry." Food Security 10 (3): 631-48.

[4] Gewona, G. K. 2018. "Comparative Gasification Process Studies for Prosopis (P. juliflora) and Rice Husks (Oryza Sp.) into Renewable Energy Resources in Kenya." Doctoral Dissertation, JKUAT-IEET.

[5] Gummert, M., and Rickman, J. F. 2006. Rice: Drying.
International Rice Research Institute, Los Baños, Philippines.

[6] Muema, F., Home, P., and Raude, J. 2018. "Application of Benchmarking and Principal Component Analysis in Measuring Performance of Public Irrigation Schemes in Kenya." Agriculture 8 (10): 162.

[7] Government of Kenya. 2009. "National Rice Development Strategic Plan (2008-2018)." Ministry of Agriculture, Nairobi.

[8] Njogu, P., Kinyua, R., Muthoni, P., and Nemoto, Y. 2015. "Thermal Gasification of Rice Husks from Rice Growing Areas in Mwea, Embu County, Kenya." Smart Grid and Renewable Energy 6: 113-9. doi: 10.4236/sgre.2015.65010.

[9] Maharashtra, I., Dutta R., and Dutt, G. S. 1981. "Producer Gas Engines in Villages of Less-Developed Countries." $\quad$ Science 213: 731-6. http://dx.doi.org/10.1126/science.

[10] Selvakumar, K. V., Umesh, A., Ezhilkumar, P., Gayatri, S., Vinith, P., and Vignesh, V. 2014. "Extraction of Silica from Burnt Paddy Husk." International Journal of ChemTech Research 6 (9): 4455-9.

[11] Yalcin, N., and Sevinc, V. 2001. "Studies on Silica Obtained from Rice Husk." Ceramics International 27 (2): 219-24.

[12] Ugheoke, B. I., Mamat, O., and Ari-Wahjoedi, B. 2013. "A Direct Comparison of Processing Methods of High Purity Rice Husk Silica." Asian Journal of Scientific Research 6 (3): 573-80.

[13] Krishnarao, R. V., Subrahmanyam, J., and Kumar, T. J. 2001. "Studies on the Formation of Black Particles in Rice Husk Silica Ash.” Journal of the European Ceramic Society 21 (1): 99-104.

[14] Fernandes, I. J., Calheiro, D., Sánchez, F. A., Camacho, A. L. D., Rocha, T. L. A. D. C., Moraes, C. A. M., et al. 2017. "Characterization of Silica Produced from Rice Husk Ash: Comparison of Purification and Processing Methods." Materials Research 20: 512-8.

[15] Kurama, H., and Kurama, S. K. 2003. "The Effect of Chemical Treatment on the Production of Active Silica from Rice Husk." In 18th International Mining Congress and Exhibition of Turkey-IMCET.

[16] Mohamed, R. M., Mkhalid, I. A., and Barakat, M. A. 2015. "Rice Husk Ash as a Renewable Source for the Production of Zeolite NaY and Its Characterization." Arabian Journal of Chemistry 8 (1): 48-53.

[17] Riveros, H., and Garza, C. 1986. "Rice Husks as a Source of High Purity Silica." Journal of Crystal Growth 75 (1): 126-31.

[18] Chakraverty, A., Mishra, P., and Banerjee, H. D. 1988. "Investigation of Combustion of Raw and Acid-Leached Rice Husk for Production of Pure Amorphous White 
Silica.” Journal of Materials Science 23 (1): 21-4.

[19] Krishnarao, R. V., Subrahmanyam, J., and Kumar, T. J. 2001. "Studies on the Formation of Black Particles in Rice Husk Silica Ash.” Journal of the European Ceramic Society 21(1): 99-104.

[20] Fidalgo, A., and Ilharco, L. M. 2001. "The Defect Structure of Sol-gel-derived Silica/polytetrahydrofuran
Hybrid Films by FTIR." Journal of Non-Crystalline Solids 283 (1-3): 144-154.

[21] Swann, G. E., and Patwardhan, S. V. 2011. "Application of Fourier Transform Infrared Spectroscopy (FTIR) for Assessing Biogenic Silica Sample Purity in Geochemical Analyses and Palaeoenvironmental Research." Climate of the Past 7(1): 65-74. 